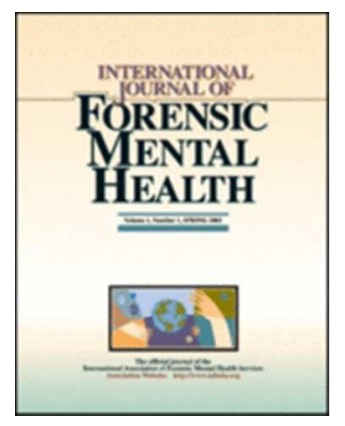

\title{
Staff experience of harassment and stalking behaviour by patients
}

\begin{tabular}{|r|l|}
\hline Journal: & International Journal of Forensic Mental Health \\
\hline Manuscript ID & UFMH-2015-049.R1 \\
\hline Manuscript Type: & Original Article \\
\hline Keywords: & Stalking, Harassment, Intrusions, Staff, Patients \\
\hline \multicolumn{3}{|c}{} \\
$\qquad \begin{array}{c}\text { SCHOLARONE } \\
\text { Manuscripts }\end{array}$ \\
\end{tabular}

URL: http://mc.manuscriptcentral.com/ufmh Email: rosenfeld@fordham.edu 


\title{
Title: Staff experience of harassment and stalking behaviour by patients
}

\author{
ABSTRACT \\ Staff from one National Health Service (NHS) Trust in England completed an online survey (N \\ $=590$ ) about their experience of intrusive behaviours from patients. These experiences were \\ categorised into either stalking or harassment and compared in terms of staff and patient \\ characteristics, types of intrusions, and aftermath. Overall, 150 were classified as being \\ stalked (25.4\%) and 172 harassed (29.2\%). There were no differences in staff characteristics \\ between the two groups. Staff from forensic services and nursing staff were particularly \\ susceptible to these intrusions which took many forms. Respondents perceived a range of \\ causes for the stalking and harassment, the most common being to gain power and \\ control/to scare. It was rare for legal sanctions to be brought against the patient. Our \\ findings reinforce the need for service providers to have policies supported with \\ preventative measures, education and a robust process for addressing stalking so that these \\ measures are embedded in practice in a way that supports staff working with patients. \\ Furthermore, service providers should be challenged on what steps they have taken to \\ prevent, and monitor, such behaviour.
}




\section{INTRODUCTION}

\section{An overview}

In England and Wales, prevalence rates for stalking among adults aged 16 to 59 years indicate that approximately one in five women and one in ten men have been stalked at some point in their lives (Chaplin, Flatley \& Smith, 2011). Stalking can have a negative impact on the victim's quality of life with undesirable psychological, social and occupational consequences (Pathé \& Mullen, 1997, 2002; Purcell, Pathé \& Mullen, 2004; Mullen, Pathé \& Purcell, 2009). Societal and professional interests in the management of stalking behaviour have grown significantly over the past decade or so. For instance, in 2010 the National Stalking Helpline was launched in the UK to provide guidance and support for victims of stalking, and in 2011 the National Stalking Clinic was launched in London to provide specialist assessment and consultation for those who have engaged in stalking behaviours. However, since its introduction into everyday lexicon in late 1980s, defining the term stalking has been fraught with difficulties not least because many of the behaviours associated with stalking overlap with people's everyday experiences such as receiving unwanted communications or being approached for a date (Purcell et al., 2004).

The legal definition of stalking has changed considerably over the years. For instance, up until 2012 people accused of stalking behaviour in England and Wales were prosecuted under harassment laws, such as the Protection from Harassment Act 1997, but the threshold was such that a charge could only be brought when these acts were deemed to cause a fear of violence. The Protection of Freedoms Act 2012 reduced such threshold by incorporating two specific offences of stalking into the Protection from Harassment Act 1997, namely 'stalking' and 'stalking involving fear of violence or serious alarm or distress'. Subsequently, the number of stalking and harassment prosecutions rose by more than $20 \%$ 
in 2014 alone and the number of cases are expected to rise further.

Behavioural scientists regard stalking as a constellation of behaviours in which a person makes repeated and persistent unwanted intrusions that cause the recipient to experience distress and fear for their safety (Mullen, Pathé, Purcell and Stuart, 1999; Purcell et al., 2004). Pathé and Meloy (2013, p.200) defined stalking as “...the repeated infliction on another of unwanted communications (e.g., through letters, telephone calls, email, and social networking websites), unwanted contacts (e.g., following and approaching), and a myriad of other harassing behaviors (e.g., malicious complaints, threats, and assaults), in a manner that causes reasonable fear and distress". Using data from an epidemiological survey in the Australian community, Purcell et al. (2004) sought to distinguish the point at which unwanted intrusions become persistent stalking based on the number of harassment methods experienced and the victim's lifestyle alterations. They defined stalking as experiencing at least two harassing intrusions which had caused fear. Purcell et al. (2004) analysed these data at one week, two week and four week cut-offs and found that two weeks was the 'critical threshold' which allowed them to discriminate between two types of intrusiveness with different impacts on victim's functioning (Purcell et al., 2004). The authors argued that this distinction was important to enable early intervention to assist the victims. Studies often use a two week cut-off (Jones \& Sheridan, 2009; Purcell, Powell \& Mullen, 2005; Whyte, Penny, Christopherson, Reiss \& Petch, 2011) although some, for example, Galeazzi, Elkins and Curci (2005) have used a four week cut-off. The number of incidents required to constitute stalking has also varied with some studies using at least two (Purcell et al., 2004), 10 (Whyte et al., 2011), or more than 10 incidents (Galeazzi et al., 2005). 
Stalking and harassment of mental health professionals

Existing literature suggests that mental health professionals, such as psychologists (Gentile, Asamen, Harmell \& Weathers, 2002; Purcell et al., 2005), psychiatrists (Whyte et al., 2011; Mclvor, Potter \& Davies, 2008; Nwachukwu, Agyapong, Quinlivan, Tobin \& Malone, 2012) and nurses (Ashmore, Jones, Jackson \& Smoyak, 2006), are particularly at high risk of being victims of stalking (for a comprehensive summary see also Pathé \& Meloy, 2013). The true prevalence rates for stalking of mental health professionals by patients are not easy to obtain given that survey response rates vary from approximately one-quarter (Whyte et al., 2011) to three-quarters (Galeazzi et al., 2005). Nevertheless, existing literature suggests that between 20\% (Mclvor et al., 2008; Purcell et al., 2005) and 40\% (Jones \& Sheridan, 2009) of mental health professionals have been stalked by patients. This is thought to be related to the observation that mental health professionals are more likely to be in contact with people who are lonely, isolated and have disordered attachment patterns (Galeazzi et al., 2005). Stalking and harassment towards staff within mental healthcare settings are under-recognised despite the high risk of occurrence, the distress caused and the impact these behaviours have on the victims (Mclvor \& Petch, 2006). For instance, victims of stalking often make changes to their professional and personal functioning such as increasing security at work or home and changing telephone numbers (Purcell et al., 2005). However, there is a risk that professionals minimise stalking in therapeutic contexts and that such incidents are under reported (Pathé \& Meloy, 2013). The evidence reviewed above suggests that mental health professionals are particularly vulnerable to the unwanted intrusions of their patients. Whilst many authors called for increased awareness amongst mental health professionals and more training around stalking (Mclvor \& Petch, 2006), very few made concrete recommendations in 
relation to how knowledge in the field could be advanced further. More specifically, what is less clear is whether the types of intrusions, antecedents, and aftermath are different for staff who have been stalked or those who have experienced lesser forms of harassment. In accordance with the conclusions reached by Purcell et al. (2004), we argue that this is an important issue to consider. Identification of staff who have been at the receiving end of stalking is crucial to facilitating effective intervention to prevent undesirable consequences for the victim. It is equally important that healthcare providers are able to recognise staff's experiences and tailor interventions as appropriate to contain the situation.

The current study

We surveyed staff with patient contact at one National Health Service (NHS) Trust to examine intrusions, categorised into either stalking or harassment, from patients. We sought to answer the following research question:

Are there any differences in the experiences of staff who have been stalked or harassed by patients in relation to: 1) staff and patient characteristics; 2 ) types of behaviours experienced; 3) perceived cause of the stalking/harassment; 4) organisational response to the stalking/harassment; 5) reason for cessation of stalking/harassment?

\section{METHOD}

\section{Setting and Participants}

Participants were staff with patient contact working in a large NHS Trust in England which employs approximately 9000 staff and provides services to a population of circa 1.1 million people. The Trust provides both forensic and non-forensic mental health services. Forensic Services provide a range of services including secure, community forensic, and prison healthcare services. Non-forensic mental health services include Adult Mental Health 
Services, Mental Health Services for Older People, Learning Disabilities, Substance Misuse Services, Psychological Therapies and Child and Adolescent Mental Health Services. Materials

We used a 29-item survey which we adapted from a survey developed by Jones and Sheridan (2009) and distributed via SurveyMonkey. The adaptations included omitting items which did not receive any positive response, combining similar items and adding questions to elicit information on whether the harassment/stalking had stopped and why. The survey collected information on basic variables (e.g., age band, ethnicity, current service affiliation, work experience). Participants were asked whether they had experienced any of 14 intrusive behaviours (e.g. hinted or boasted of information they have gained about you) from current or former patients, and how many patients they experienced these behaviours from $(1,2,3,4$ or more ).

Participants were then asked to respond to subsequent questions by focussing on the experience that affected them the most. Using a five-point Likert scale (not at all, slightly, moderately, very, unbearably) participants were asked to rate how distressed, and how fearful, each of the applicable 14 intrusive behaviours made them feel. Participants were then asked to identify how often these intrusions occurred and whether they classed it as stalking. They were then asked to provide some basic information about the characteristics of the patient who carried out the harassment/stalking behaviours, in terms of gender, age, ethnicity and type of mental disorder. Participants were then asked to identify the perceived cause from a list of 12 options (e.g., delusional beliefs). Participants were prompted to indicate how they responded to the behaviours from a list of six strategies (e.g. took extra security precautions) and to rank the helpfulness of the response on a 7-point Likert scale. Participants then identified their experiences following the 
harassment/stalking from a list of 18 potential responses (e.g. panic attacks, felt concern for the patient.) Participants were asked about how the organisation responded and whether they agreed with a list of nine statements (e.g. my organisation did enough to protect my physical safety). They were then asked about the eventual outcome and what made the behaviour stop (e.g. change in your location). Participants were then given the chance to give any additional comments.

Procedure

We emailed staff the study outline and the link to the survey. We also advertised the survey on the Trust intranet. Staff were informed that their participation was voluntary and asked to be as open and honest as possible when completing the survey. Participants were advised to contact the National Stalking Helpline should they feel the need for additional support or advice after completing the survey (phone number and website details were provided). The survey took approximately between 15 and 30 minutes to complete. Definition of stalking employed in current study

Respondents met the operational definition of stalking if the behaviours occurred for more than two weeks and they had been at least 'slightly fearful'. Purcell et al., (2004) identified two weeks as a reliable cut-off for stalking. Any other intrusions which did not meet this definition were classed as harassment. Additionally, respondents were then asked "Would you class this as stalking?"

Ethics and Consent

Since our study was a staff survey that did not involve access to identifiable patient data, research ethics approval to conduct the study was not required. The Research Governance Department of Trust granted approval to conduct the study. Participants were informed that completing and submitting the survey would indicate that they have given 
implicit consent to participate. Participants completed the survey anonymously in order to protect confidentiality and each participant was assigned an identity code so that no names would appear on the database.

Statistical analyses

All analyses were conducted using the Statistical Package for the Social Sciences (SPSS), Version 19. Chi-square tests were used to examine categorical data. Odds ratios (OR) and $95 \%$ confidence intervals $(\mathrm{Cl}$ ) are reported. Effect sizes (Phi) are reported in the tables. The level of statistical significance was defined as an alpha less than .05. All analyses were two-tailed. Corrections for potential false discoveries were made given the number of comparisons undertaken by controlling for the False Discovery Rate (FDR; Benjamini \& Hochberg, 1995). The FDR was calculated for each step of analyses (e.g. perceived cause of stalking or harassment).

\section{RESULTS}

Sample characteristics

All Trust employees (approximately 9000) were emailed the study outline. Only those with some level of patient contact in their professional roles were invited to participate in the survey, and since not all who received the email were eligible to participate, it has not been possible to estimate the response rate. In total, 707 members of staff responded to the survey. Of these, $441(62.4 \%)$ indicated that they had been harassed. However, 117 were excluded from the analyses because they either did not provide further information despite indicating they had been harassed $(n=74)$ or their response was inconsistent (e.g. they indicated they had been harassed but stated that none of the example behaviours applied; $n=38$ ). Therefore the final sample comprised 590 members of 
staff, 444 (75.3\%) women and $146(24.7 \%)$ men. There were 178 respondents from forensic services (30.2\%) and 412 respondents from non-forensic services (69.8\%).

In terms of ethnicity, the participants identified their ethnicity as follows: 543

(92.0\%) White; 10 (1.7\%) Black African; 5 (0.8\%) Black Caribbean; 15 (2.5\%) Asian; and 17

(2.9\%) other. The majority of participants were aged between 20 and 59 years: $20-29$ years

$(n=94 ; 15.9 \%) ; 30-39$ years $(n=167 ; 28.3 \%) ; 40-49$ years $(n=171 ; 29.0 \%)$; and $50-59$ years

( $n=132 ; 22.4 \%)$. In terms of professional group, the majority $(n=262 ; 44.4 \%)$ were nurses.

The remainder were from the disciplines of psychology $(n=53 ; 9.0 \%)$, occupational therapy

( $n=50 ; 8.5 \%)$, psychiatry $(n=42 ; 7.1 \%)$, and others $(n=183 ; 31.0 \%)$ such as social work,

education and administration. Service affiliation was identified as follows: 86 (14.6\%)

forensic nursing, 92 (15.6\%) forensic non-nursing, 176 (29.8\%) non-forensic nursing, and 236

(40.0\%) non-forensic non-nursing. Respondents had a range of experience of working within

mental health services with more than two-thirds having over 5 years' experience: 52 (8.8\%)

had worked for less than one year; 127 (21.5\%) 1-5 years; 239 (40.5\%) 6-15 years; 143

(24.2\%) $16-30$ years; and 29 (4.9\%) with over 30 years' experience.

Intrusive behaviours

In total, 322 participants (54.6\%) indicated that they had experienced one or more intrusive behaviours from at least one patient. Out of the 590 respondents, significantly more men $(n=92 ; 63.0 \%)$ than women $(n=230 ; 51.8 \%)$ indicated that they had experienced intrusive behaviours from a patient, $\left(\chi^{2}[1, n=590]=5.571, p=.018 ; O R=1.59\right.$ [95\% Cl 1.08-2.33]). Significantly more nursing staff $(n=178 ; 67.9 \%)$ than non-nursing staff ( $n=144 ; 43.9 \%)$ indicated that they had experienced intrusive behaviours from a patient $\left(\chi^{2}[1, n=590[=33.945, p<.001 ; O R=2.71[95 \% \mathrm{Cl} 1.93-3.80])\right.$. Significantly more forensic staff $(n=128 ; 71.9 \%)$ than non-forensic staff $(n=194 ; 47.1 \%)$ indicated that they had 
experienced intrusive behaviours from a patient $\left(\chi^{2}[1, n=590[=30.894, p<.001 ; O R=2.88\right.$ $[95 \% \mathrm{Cl} 1.97-4.21])$.

The experience of stalking and harassment

We categorised the responses from the 322 staff who had experienced these intrusive behaviours to indicate whether the experience constituted harassment or stalking. Stalking comprised behaviours that occurred for more than two weeks and induced at least slight fear $(n=150)$. Harassment comprised responses not meeting these criteria $(n=172)$. Staff and patients characteristics

There was no difference between the proportion of men $(n=39 ; 26.7 \%)$ and women $(n=111 ; 25.0 \%)$ who had been stalked by a patient $\left(\chi^{2}[1, n=590[=.170, p=.680 ; O R=1.09\right.$ [95\% Cl 0.71-1.67]). Significantly more nursing staff $(n=87 ; 33.2 \%)$ than non-nursing staff ( $n$ $=63 ; 19.2 \%)$ had been stalked by a patient $\left(\chi^{2}[1, n=590]=15.05, p<.001 ; O R=2.09[95 \% \mathrm{Cl}\right.$ 1.44-3.05]). Significantly more forensic staff $(n=64 ; 36.0 \%)$ than non-forensic staff $(n=86$; $20.9 \%)$ had been stalked by a patient $\left(\chi^{2}[1, n=590]=14.911, p<.001 ; 0 R=2.13[95 \% \mathrm{Cl}\right.$ 1.44-3.14]).

A log-linear analysis was conducted in order to investigate three two-way interactions (stalked $\mathrm{x}$ nursing; stalked $\mathrm{x}$ forensic and nursing $\mathrm{x}$ forensic) and one three-way interaction (stalked $\mathrm{x}$ nursing $\mathrm{x}$ forensic). The three-way log-linear analysis produced a final model that retained the stalked $x$ nursing $x$ forensic interactions $\left(\chi^{2}[2]=0.953, p=.62\right)$. The stalked $\times$ forensic interaction was significant $\left(\chi^{2}[1]=13.21, p<.001\right)$. The stalked $\times$ nursing interaction was also significant $\left(\chi^{2}[1]=13.85, p<.001\right)$. The forensic $x$ nursing interaction was not significant $\left(\chi^{2}[1]=0.428, p=.513\right)$.

There were no significant differences between staff characteristics in the harassment and stalking categories on age, sex, ethnicity, profession (nursing or non-nursing), amount 
of experience, and specialty (forensic or non-forensic).

No significant differences were identified in the characteristics of the patient (sex, age, ethnicity, setting, diagnosis) who harassed or stalked the member of staff. The majority of both stalking $(111 / 145 ; 76.6 \%)$ and harassment $(97 / 145 ; 66.9 \%)$ occurred in inpatient settings rather than other settings. The majority of patients who stalked $(121 / 145 ; 83.4 \%)$ or harassed $(114 / 145 ; 78.6 \%)$ staff were men.

Type of intrusive behaviours experienced by those stalked or harassed

We then examined the types of behaviours associated with the stalking or harassment episode (see Table 1). For nine of the fourteen behaviour options, staff who had been stalked were significantly more likely than staff who had been harassed to have experienced that behaviour. Having had sexual comments made about them was the most common experience for those who had been stalked (58.0\%) and those who had been harassed (45.3\%). More than half of those who had been stalked had also received direct or indirect threats towards them or someone close to them.

INSERT TABLE 1

Respondents were asked whether they classed the experience as stalking. Of the 150 staff who met the operational definition of stalking, 36 (24.0\%) classed the experience as stalking. Of the 152 respondents from the 172 staff who met the operational definition of harassment, 11 (7.2\%) classed the experience as stalking. Therefore 47 (8.0\%) of the initial 590 respondents self-classified that they had been stalked. In contrast, the operational definition indicated 150 (25.4\%) of the initial 590 respondents had been stalked. 
Perceived cause of the harassment/stalking

Participants were asked about the perceived causes of the harassment/stalking.

There were 130 and 143 responses from staff in the harassed and stalked groups

respectively (see Table 2 ). The most common reason given by staff who had been

harassed/stalked was to gain power and control or to scare. Compared to those harassed,

those stalked were significantly more likely to attribute the cause to anger and hostility

$\left(\chi^{2}[1, N=273]=9.92, p=.002 ; O R=2.24[95 \% \mathrm{Cl} 1.35-3.71]\right)$ and a desire for

intimacy/romantic relationship $\left(\chi^{2}[1, N=273)=7.86, p=.005 ; O R=2.15[95 \% \mathrm{Cl} 1.25-3.68]\right)$.

\section{INSERT TABLE 2}

\section{Organisational response to harassment/stalking}

Staff were asked about the support they received following the harassment/stalking.

There were 125 and 137 responses from staff in the harassed and stalked groups

respectively. There were no significant differences in the responses between those stalked

or harassed after adjusting for the FDR (see Table 3). The majority of those stalked and

harassed felt supported by immediate colleagues and the organisation. Half of those stalked

or harassed felt that they should handle the situation within the therapeutic relationship.

One-quarter of those harassed, and over one-third of those stalked, reported that they felt

obliged to carry on working with the patient even when they did not want to. Similarly, onequarter felt they were expected to deal with the situation on their own.

INSERT TABLE 3

URL: http://mc.manuscriptcentral.com/ufmh Email: rosenfeld@fordham.edu 
Reasons for the harassment/stalking behaviour ceasing

Staff were asked about the reasons why the harassment behaviours stopped. There were 83 and 104 responses from staff in the harassed and stalked groups respectively (see Table 4). Compared to those harassed, those stalked were significantly more likely to report that the reason for it stopping was a change in the staff member's location $\left(\chi^{2}[1, N=187]=\right.$ $6.72, p=.01 ; \mathrm{OR}=2.35[95 \% \mathrm{Cl} 1.22-4.52])$ and a change in the location of the patient $\left(\chi^{2}[1\right.$, $\mathrm{N}=187]=14.17, \mathrm{p}=.001 ; \mathrm{OR}=3.85[95 \% \mathrm{Cl} 1.86-7.97])$. Conversely, compared to those stalked, those harassed were significantly more likely to report that the patient responded to treatment, $\left(\chi^{2}[1, N=187]=9.02, p=.003 ; O R=2.52[95 \% \mathrm{Cl} 1.37-4.65]\right)$. Furthermore, legal sanctions were rare - only nine participants reported this as a reason for the intrusions stopping.

\section{INSERT TABLE 4}

\section{DISCUSSION}

We explored the experiences of a range of staff with patient contact and described the extent of stalking and, less intrusive, harassment by patients. More than half of the respondents reported they had experienced intrusive behaviours from at least one patient. Of these, almost half were classified as being stalked. Staff from forensic services and nursing staff were particularly susceptible to being harassed or stalked by patients. Perhaps forensic professionals are at a higher risk because forensic patients stay longer in hospital making it more likely for them to develop dysfunctional attachments patterns toward staff. Furthermore, forensic practitioners manage people with complex psychopathology, such as 
psychosis and personality disorder, both disorders have been linked with an elevated risk of stalking, as well as criminal histories (McEwan, Mullen \& Mackenzie, 2009; Mclvor et al, 2008; Mullen et al., 1999).

Respondents experienced a range of intrusions although those in the stalking group had experienced more types of intrusions that those in the harassed group. It is likely that staff were not aware of the distinction between harassment and stalking because as with other studies (e.g., Jones \& Sheridan, 2009), the majority of respondents who met the operational definition of stalking did not self-classify the experience as being stalked.

Our stalking and harassment groups differed slightly from that of Purcell et al. (2004) in that they obtained a sample of people, from the general population, who had experienced intrusive behaviours which had caused fear and they differentiated these groups only by the duration of the behaviours. In contrast, our harassment group also contained intrusive behaviours which did not cause fear. However, similar to Purcell et al. (2004), we found that gender and age did not differentiate the stalked and harassed groups. There was no difference between the rate of men and women who had been stalked by a patient despite more men than women experiencing intrusive behaviours - this was also found in a community forensic service sample (Jones \& Sheridan, 2009).

Although the majority of staff who had been stalked/harassed felt they had some support at work, one-quarter felt there was a lack of support from the organisation. Specifically, one-fifth of those in the stalking group reported that they were told or made to feel that they were over-reacting or being paranoid. However, this does not necessarily reflect current practice as these experiences could potentially have occurred several years ago. Nonetheless, service providers have a duty of care to their employees and should be aware that stalking by patients presents a risk to staff. There should not be a culture of 
tolerance (MacKensie \& James, 2011).

Jones and Sheridan (2009) identified anger and hostility as the most common perceived cause of stalking. We found respondents in the stalking group were more likely than those in the harassment group to perceive anger and hostility as the cause of the intrusions. Service providers should pay special attention to patients who express anger and hostility to help safeguard employees.

A change in the location of the staff member or the patient was the most common reason why the stalking/harassment behaviours ceased. However, it was not possible to determine whether the change in location was in response to the intrusions. More respondents in the harassed group perceived that patients had responded to treatment. This may be because treatment improved behaviour and consequently the intrusions did not progress to stalking. Alternatively, patients who responded to treatment may have been discharged from the service more quickly. There were a range of other reasons why the behaviours ceased although it was rare for legal sanctions to be brought against the patient. Perhaps in future there will be more legal sanctions following new stalking legislation in England and Wales, although such sanctions may be ineffective without appropriate treatment (MacKenzie \& James, 2011).

Studies have identified the high rates of stalking victimization among mental health workers (e.g. Gentile et al., 2002; Ashmore et al., 2006) and so service providers should be challenged on what steps they have taken to prevent, and monitor, such behaviour. Mental health workers should be made aware that unwanted intrusions by patients which cause fear, go beyond harassment, and is stalking. This is particularly important given that respondents are not good at recognising that they have been stalked. Furthermore, mental health professionals may perceive their role offers protection from stalking (MacKensie \& 
James, 2011).

Our findings reinforce the need for policies to be supported with preventative measures, education and a robust process for addressing stalking so that these measures are embedded in practice in a way that supports staff working with patients. Particular attention should be given to identifying members of staff who have been experiencing stalking from patients. It is important that early intervention is facilitated to prevent undesirable consequences for the victim. Furthermore, almost one-third of respondents felt obliged to continue working with the patient. This is likely to have implications for the therapeutic relationship. Current service users' stalking behaviours should be addressed in treatment plans and risk management plans.

When asked if there was anything else they would like to add, several participants commented that they were pleased to participate and be given an opportunity to report their concerns. While this survey focussed on the behaviour of patients, some participants commented that the main source of harassment came from patients' relatives or other members of staff. Other studies have found patients were the perpetrators of between oneto two-thirds of stalking where surveys included any type of stalker (Ashmore et al., 2006; Whyte et al., 2011). Furthermore, Woodrow and Guest (2012) found harassment from staff members had a stronger negative association in levels of nurses' well-being than being subjected to violence from members of the public.

\section{Limitations}

We could not ascertain an accurate response rate - it was perhaps in the region of $10 \%$. Nevertheless, we do not know if staff who had been harassed or stalked would be more or less likely to participate. Staff not familiar with, or comfortable using IT, may have been dissuaded from completing the survey via SurveyMonkey. 
Part of the survey asked participants to focus on the episode that caused the most distress. However, some participants commented they found it difficult to separate some of the incidents. Furthermore, some participants did not provide responses to some of the questions such as the perceived cause of, or their response to, the harassment/stalking. It was not clear why some responses were omitted but this led to reduced sample sizes for some questions. Although participants were asked whether these intrusive behaviours had stopped or were still ongoing, additional information on the timings and recency the harassment/stalking should have been sought. Accordingly, it is possible that some of the responses relate to harassment/stalking during previous employment in other Trusts or in other locations. Furthermore, it was not possible to show whether the responses are congruent with current guidance and support from the Trust.

We did not ask participants whether they took specific precautions to avoid being stalked, and if so which precautions. These data could have been used to assess awareness of the issues. Studies have reported that psychiatrists took steps to limit their personal information being publicly accessible (Mclvor et al., 2008; Nwachukwu et al., 2012). For example, Nwachukwu and colleagues found that $79 \%$ of psychiatrists deliberately did not have their name in the phone directory, $10 \%$ did not have their name in the electoral register, $61 \%$ withheld their phone number during calls and $42.7 \%$ avoided social network internet sites (Nwachukwu et al., 2012).

We surveyed staff from one NHS Trust in England which provides a number of services including a unique range of forensic services. Therefore any generalisation to other Trusts will be limited.

Conclusion and directions for future research 
The prevalence of stalking and harassment indicates that mental health organisations should have policies and procedures in place to educate and support staff. Induction programmes for new staff (and students) should address stalking and harassment from patients and what steps should be taken in response to this. Similarly, training should be available for staff to raise awareness of the risks, and supervision sessions should encourage staff to disclose any current experiences of harassment and stalking.

While this survey focused on the patients as the perpetrators of harassment and stalking, future studies of staff should be expanded to capture their experiences where the perpetrators were the patients' relatives or other members of staff. Furthermore, all staff should be asked what precautions they were taking to avoid being stalked/harassed. Similarly, more information on recent episodes of stalking and the specific responses after the episode would help assess the efficacy of awareness training and adherence to the relevant policies.

\section{REFERENCES}

Ashmore, R., Jones, J., Jackson, A., \& Smoyak, S. (2006). A survey of mental health nurses' experiences of stalking. Journal of psychiatric and mental health nursing, 13(5), 562569.

Benjamini, Y., \& Hochberg, Y. (1995). Controlling the false discovery rate: a practical and powerful approach to multiple testing. Journal of the Royal Statistical Society. Series $B$ (Methodological), 289-300.

Chaplin, R., Flatley, J., \& Smith, K. (2011). Crime in England and Wales 2010/11: Findings from the British Crime Survey and police recorded crime $\left(2^{\text {nd }}\right.$ ed). HOSB:10/11. London: Home Office. 2011. Available at https://www.gov.uk/government/uploads/system/uploads/ attachment_data/file/116417/hosb1011.pdf [last accessed May 6 2015]

Galeazzi, G. M., Elkins, K., \& Curci, P. (2005). Emergency psychiatry: The stalking of mental health professionals by patients. Psychiatric Services, 56(2), 137-138. 
Gentile, S. R., Asamen, J. K., Harmell, P. H., \& Weathers, R. (2002). The stalking of psychologists by their clients. Professional Psychology: Research and Practice, 33(5), 490-494.

Jones, L., \& Sheridan, L. (2009). Stalking and harassment of mental health professionals by patients in a community forensic service. The British Journal of Forensic Practice, 11(1), 30-37.

MacKenzie, R. D., \& James, D. V. (2011). Management and treatment of stalkers: problems, options, and solutions. Behavioral Sciences \& the Law, 29, 220-239.

McEwan, T. E., Mullen, P. E., MacKenzie, R. D., \& Ogloff, J. R. (2009). Violence in stalking situations. Psychological medicine, 39(09), 1469-1478.

Mclvor, R. J., \& Petch, E. (2006). Stalking of mental health professionals: an underrecognised problem. The British Journal of Psychiatry, 188(5), 403-404.

Mclvor, R. J., Potter, L., \& Davies, L. (2008). Stalking behaviour by patients towards psychiatrists in a large mental health organization. International journal of social psychiatry, 54(4), 350-357.

Mullen, P. E., Pathé, M., \& Purcell, R. (2009). Stalkers and their victims ( $2^{\text {nd }}$ ed.). Cambridge, UK: Cambridge University Press.

Mullen, P. E., Pathé, M., Purcell, R. \& Stuart, G. W. (1999). Study of Stalkers. American Journal of Psychiatry, 156(8), 1244-1249.

Nwachukwu, I., Agyapong, V., Quinlivan, L., Tobin, J., \& Malone, K. (2012). Psychiatrists' experiences of stalking in Ireland: prevalence and characteristics. The Psychiatrist, 36(3), 89-93.

Pathé, M. T., \& Meloy, J. R. (2013). Commentary: Stalking by Patients-Psychiatrists' Tales of Anger, Lust and Ignorance. Journal of the American Academy of Psychiatry and the Law Online, 41(2), 200-205.

Pathé, M., \& Mullen, P. E. (1997). The impact of stalkers on their victims. The British Journal of Psychiatry, 170(1), 12-17.

Pathé, M., \& Mullen P. E. (2002). The victim of stalking. In: J Boon \& L Sheridan (Eds) Stalking and Psychosexual Obsession: Psychological perspectives for prevention, policing and treatment. Chichester: John Wiley and Sons.

Purcell, R., Pathé, M., \& Mullen, P. (2004). Editorial: When do repeated intrusions become stalking? Journal of Forensic Psychiatry \& Psychology, 15(4), 571-583.

Purcell, R., Powell, M. B., \& Mullen, P. E. (2005). Clients Who Stalk Psychologists: Prevalence, Methods, and Motives. Professional Psychology: Research and Practice, 36(5), 537- 
543.

Whyte, S., Penny, C., Christopherson, S., Reiss, D., \& Petch, E. (2011). The stalking of psychiatrists. International Journal of Forensic Mental Health, 10(3), 254-260.

Woodrow, C., \& Guest, D. E. (2012). Public violence, staff harassment and the wellbeing of nursing staff: an analysis of national survey data. Health Services Management Research, 25(1), 24-30.

URL: http://mc.manuscriptcentral.com/ufmh Email: rosenfeld@fordham.edu 
Table 1: Types of Behaviour Experienced by Staff who have been Harassed or Stalked

\begin{tabular}{|c|c|c|c|c|c|}
\hline Behaviour & $\begin{array}{c}\text { Harassed }(\mathrm{N}=172) \\
\mathrm{n}(\%)\end{array}$ & $\begin{array}{c}\text { Stalked }(\mathrm{N}=150) \\
\mathrm{n}(\%)\end{array}$ & chi & $p$ & Phi \\
\hline Made sexual comments about you & $78(45.3)$ & $87(58.0)$ & 5.133 & .023 & .126 \\
\hline $\begin{array}{l}\text { Made direct or indirect threats towards } \\
\text { you or those close to you }\end{array}$ & $53(30.8)$ & $78(52.0)$ & 14.903 & .001 & .215 \\
\hline Touched or grabbed you & 58 (33.7) & $70(46.7)$ & 5.607 & .018 & .132 \\
\hline $\begin{array}{l}\text { Made reference to knowing where you } \\
\text { live and/or contacted colleagues to find } \\
\text { out about your whereabouts }\end{array}$ & $43(25.0)$ & $70(46.7)$ & 16.513 & .001 & .226 \\
\hline $\begin{array}{l}\text { Made false accusations, spread rumours } \\
\text { about you or attacked your professional } \\
\text { reputation }\end{array}$ & $53(30.8)$ & $72(48.0)$ & 9.964 & .002 & .176 \\
\hline Asked you out & $42(24.4)$ & $54(36.0)$ & 5.136 & .023 & .126 \\
\hline $\begin{array}{l}\text { Hinted or boasted of information they } \\
\text { have gained about you }\end{array}$ & $36(20.9)$ & $56(37.3)$ & 10.564 & .001 & .181 \\
\hline $\begin{array}{l}\text { Sent you unwanted letters/emails/notes } \\
\text { without appropriate cause }\end{array}$ & $13(7.6)$ & $42(28.0)$ & 23.640 & .001 & .271 \\
\hline $\begin{array}{l}\text { Made unwanted phone calls, silent calls, } \\
\text { sent unwanted text messages or left } \\
\text { repeated messages on your answer } \\
\text { machine }\end{array}$ & $19(11.0)$ & $28(18.7)$ & 3.732 & .053 & .108 \\
\hline $\begin{array}{l}\text { Followed you, repeatedly approached } \\
\text { you outside work or loitered outside } \\
\text { your workplace/ home }\end{array}$ & $14(8.1)$ & $29(19.3)$ & 8.677 & .003 & .164 \\
\hline Left unwanted items for you to find & $8(4.7)$ & $15(10.0)$ & 3.456 & .063 & .104 \\
\hline $\begin{array}{l}\text { Been physically and/or sexually violent } \\
\text { towards you outside clinical contact }\end{array}$ & $6(3.5)$ & $8(5.3)$ & 0.656 & .418 & .045 \\
\hline Written graffiti about you & $11(6.4)$ & $5(3.3)$ & 1.591 & .207 & .070 \\
\hline $\begin{array}{l}\text { Broken into your home or workplace } \\
\text { and/or stolen any of your possessions }\end{array}$ & $3(1.7)$ & $2(1.3)$ & FET & 1.000 & .017 \\
\hline
\end{tabular}

Note: Benjamini and Hochberg (1995) corrected significance level $<=0.032$ rather than $<.05$ 
Table 2: Perceived cause of harassment or stalking [frequency (\%)]

\begin{tabular}{lccccc}
\hline Perceived cause & Harassed & Stalked & Chi & $p$ & Phi \\
& $\mathrm{N}=130$ & $\mathrm{~N}=143$ & & & \\
\hline Desire for intimacy/romantic relationship & $28(21.5)$ & $53(37.1)$ & 7.865 & .005 & .0170 \\
Rejection/end of therapeutic relationship & $9(6.9)$ & $21(14.7)$ & 4.195 & .041 & .124 \\
To gain power and control/to scare & $54(41.5)$ & $70(49.0)$ & 1.509 & .219 & .074 \\
Delusional beliefs & $28(21.5)$ & $47(32.9)$ & 4.386 & .036 & .127 \\
Anger and hostility & $36(27.7)$ & $66(46.2)$ & 9.917 & .002 & .191 \\
Jealousy & $7(5.4)$ & $11(7.7)$ & .0 .589 & .443 & .046 \\
Projection of blame (a grudge) & $19(14.6)$ & $33(23.1)$ & 3.162 & .075 & .108 \\
Dependency & $16(12.3)$ & $31(21.7)$ & 4.195 & .041 & .124 \\
Socially incompetent & $32(24.6)$ & $38(26.6)$ & 0.137 & .711 & .022 \\
Resentment, supposed injury or dereliction & $16(12.3)$ & $18(12.6)$ & .005 & .944 & .004 \\
Support seeking/desire for care & $46(35.4)$ & $47(32.9)$ & 0.192 & .661 & .192 \\
\hline
\end{tabular}

Note: Benjamini and Hochberg (1995) corrected significance level $<=0.009$ rather than $<.05$ 
Table 3: Response to harassment or stalking [n (\%)]

\begin{tabular}{lccccc}
\hline Agree with the following 262 responses & $\begin{array}{c}\text { Harassed } \\
\mathrm{N}=125\end{array}$ & $\begin{array}{c}\text { Stalked } \\
\mathrm{N}=137\end{array}$ & chi & $p$ & Phi \\
\hline $\begin{array}{l}\text { In general I felt supported by my } \\
\text { organisation }\end{array}$ & $94(75.2)$ & $99(72.3)$ & .291 & .590 & -.033 \\
$\begin{array}{l}\text { I felt supported by my immediate } \\
\text { colleagues }\end{array}$ & $115(92.0)$ & $124(90.5)$ & .181 & .671 & -.026 \\
$\begin{array}{l}\text { My organisation did enough to protect my } \\
\text { physical safety }\end{array}$ & $96(76.8)$ & $97(70.8)$ & 1.212 & .271 & -.068 \\
$\begin{array}{l}\text { I was told or made to feel that I was over- } \\
\text { reacting/being paranoid }\end{array}$ & $15(12.0)$ & $29(21.2)$ & 3.932 & .047 & .122 \\
$\begin{array}{l}\text { I was expected to deal with it on my own } \\
\text { I felt that I should handle it within the }\end{array}$ & $28(22.4)$ & $35(25.5)$ & .355 & .552 & .037 \\
$\begin{array}{l}\text { therapeutic relationship } \\
\text { I felt reluctant to involve the police because } \\
\text { of the patient's mental disorder }\end{array}$ & $64(51.2)$ & $72(52.6)$ & .048 & .826 & .014 \\
$\begin{array}{l}\text { I felt obliged to carry on working with the } \\
\text { patient even when I didn't want to } \\
\text { I felt worried that others would see it as } \\
\text { reflecting badly on me professionally }\end{array}$ & $30(24.0)$ & $51(37.2)$ & 2.523 & .112 & .098 \\
\hline
\end{tabular}

Note: Benjamini and Hochberg (1995) corrected significance level = all non-significant 
Table 4: Reasons for cessation of harassment or stalking [n (\%)]

\begin{tabular}{lrrrrrr}
\hline Reason for stopping 187 responses & Harassed & Stalked & chi & $p$ & Phi \\
& $\mathrm{N}=83$ & $\mathrm{~N}=104$ & & & \\
\hline Change in the location of the patient & $12(14.5)$ & $41(39.4)$ & 14.166 & .001 & .275 \\
Change in your location & $18(21.7)$ & $41(39.4)$ & 6.724 & .010 & .190 \\
Legal sanctions & $3(3.6)$ & $6(5.8)$ & $\mathrm{FET}$ & .733 & .050 \\
Patient discharged from the service & $21(25.3)$ & $34(32.7)$ & 1.215 & .270 & .081 \\
Patient transferred to another service & $9(10.8)$ & $19(18.3)$ & 2.000 & .157 & .103 \\
Patient transferred to another worker & $14(16.9)$ & $13(12.5)$ & 0.713 & .399 & .062 \\
Restricted activity of the patient & $12(14.5)$ & $12(11.5)$ & 0.352 & .553 & .043 \\
The patient responded to treatment & $40(48.2)$ & $28(26.9)$ & 9.024 & .003 & .220 \\
\hline
\end{tabular}

Note: Benjamini and Hochberg (1995) corrected significance level $<=0.019$ rather than $<.05$

URL: http://mc.manuscriptcentral.com/ufmh Email: rosenfeld@fordham.edu 